\title{
Stakeholder Theory at the Cross Road: A Holistic Model for Business Government and Society
}

\author{
Yaprak Anadol \\ University of Dubai \\ Mail : yanadol@ud.ac.ae
}

\begin{abstract}
Stakeholder theory is one of the most accepted models explaining the business government and society. This short theory paper examines various issues related to the stakeholder theory in terms of several critical tensions, including the scope of the model, justice and efficiency considerations and value co-creation. The main contribution of this paper is to introduce the human factor as a focal point leading the social value co-creation and present profit optimization alternative rather than the profit maximization. Consumer perspective and role overlaps are emphasized and some concluding observations are provided with a suggested holistic model for the business government and society relationship.
\end{abstract}

Keywords : stakeholder theory, business government and society, value cocreation, Justice, effectiveness

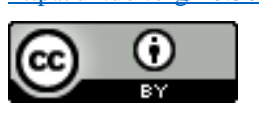

2523-6547 - Copyright: (C) 2017 The Authors. This is an open access article distributed under the terms of the Creative Commons Attribution License, which permits unrestricted use, distribution, and reproduction in any medium, provided the original author and source are credited. 


\section{Introduction}

The relationship between business, government and society is an evolving phenomenon since late 18th and early 19th century. Following the development of neoclassic economic theory, market capitalism model and especially managerial capitalism model has been criticized by many scholars and an alternative model has been introduced by Freeman (1984), conceptualized as stakeholder theory of the firm.

In the following sections this theory paper indicates a series of issues related to the stakeholder theory in terms of several critical tensions, including the scope of the model, justice and efficiency considerations and value cocreation. Finally a model will be suggested as an alternative extension of the stakeholder model.

\section{Stakeholder Model}

The stakeholder model has carried many forms. It has been represented as a stakeholder model, stakeholder thinking, stakeholder theory or even a state of art, which are considered as a framework for business, society and government relationship (Freeman, 1984; Parmar et al. 2010). The theory is based on a model suggesting to place the business in the middle as the center of the economic activity and to locate other institutions and parties around it.

Stakeholder is defined as an entity that is benefitted or burdened by the actions of a corporation or whose actions may benefit or the burden the corporation (Steiner and Steiner 2012). The focal point in the model is the "company" and the rest of the parties which are directly or indirectly in relationship with the company are the surrounding stakeholders (Freeman, 1984).

The model redirects the modern corporations' attention from the stockholders/shareholders to stakeholders and it also debates legal and economic aspects of this directional change which has been discussed by many scholars presenting counterarguments whether a corporation's responsibility is primarily (or only) to deliver profits to the stockholders/owners.

There are many debates around the critical tensions around stakeholder theory which leads a critical review of the model, especially the scope of the model which clearly determined by Phillips et. al (2003). Since 2003 this notion has been stretched by many parties which are lead to the extensive usage of stakeholder context. As corporations are getting stronger in time through their increasing economy of scale and the through the changing global dynamics, stakeholder theory become one of the most powerful perspective targeting theory of organizational management and ethics (Philips et.al 2003). 


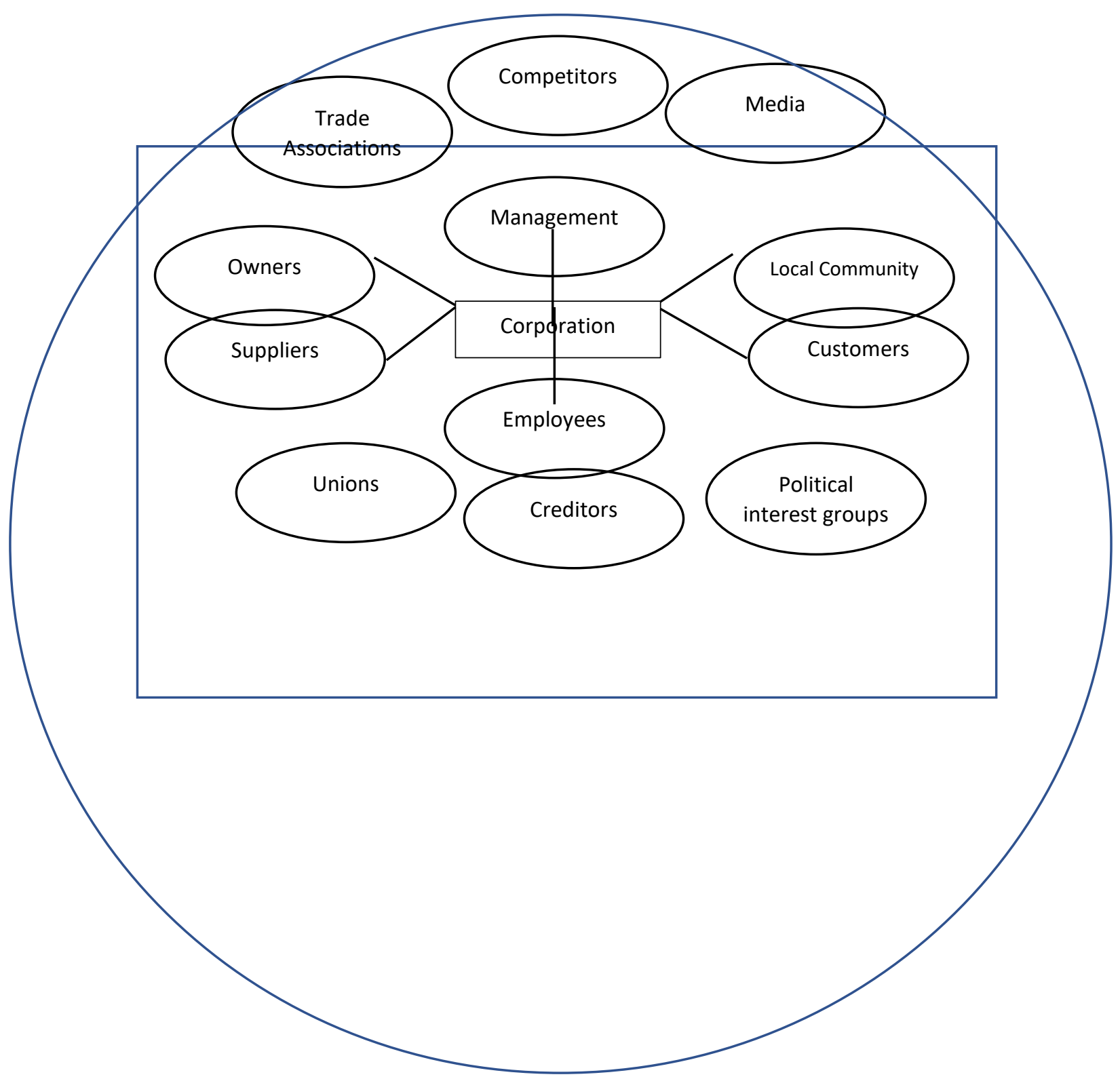

Figure 1. Original Model (Freeman 1984) depicted in the box with extension of the stakeholders of the corporation (Steiner and Steiner, 2011 pg 17)

Despite various counter opinions, stakeholder framework has been widely accepted at many platforms, not only by the academics but also by many companies and institutions (Agle et. al., 2008). Even Pope Benedict XVI stated that:

" .... the responsibility of the business should extend to the other stakeholders who contribute the business life." (Steiner and Steiner, 2012).

Lately it is emphasized in 2016 UN Global Compact SDGs (Sustainable Development Goals) forum, and PRME (Principle for Responsible Management Education) meeting in Dubai that multinational companies and businesses have great responsibilities towards their stakeholders as being the major player of economic activities. 
Many discussions regarding to the stakeholder theory is related to theory construction of the model (Donaldson \& Preston, 1995). The critics involve the justification problem which targets the descriptive, instrumental and normative usage of the theory. It is suggested that these aspects are nested in each other where descriptive justifications indicate that observed reality corresponds with the embedded concepts of theory; instrumental justification provides evidence regarding connection between the stakeholder management and company performance. Normative justification, on the other hand, attempts to provide "what is right" for individual and group, social contract and or utilitarianism.

As its formation, stakeholder theory contains the basic formation of the theory. As Whetten (1989) describes in his paper, a complete theory must contain four essential elements (Dubin, 1978). The first element is related to what question describing which factors, variables, constructs or concepts are logically need to be considered as part of the explanation of the phenomena. Second element is related to how question. This element investigates how these factors are related towards causality. What and how questions describe the phenomenon by providing a framework for interpreting patterns from which testable propositions can be derived.

The third element is related to why question which explains the essential justification of psychological, economic or social dynamics of the selected factors and proposed casual relationships. Why question explains the phenomenon by providing a theoretical direction which then generates methodological debates over the link between theory development and empirical research. Here different perspectives from other fields are adopted through which the metaphors and gestalts are utilized to encounter fundamental rationales supporting accepted theories. Stakeholder theory is using various interdisciplinary approaches and find various applications in social psychology, business ethics, corporate social responsibility and marketing (Vilanova, 2007, Richards, 2004) The fourth element describes the Who, were and when questions which serves the limitation of the propositions of the theoretical model which stimulates the investigation of qualitative changes in the boundaries of a theory (Whetten, 1989)

Stakeholder theory with its descriptive, normative and instrumental nature fulfils the fundamental expectation of a theory as its link to the other disciplines like accounting finance, marketing business ethics and corporate social responsibility and their applications and boundaries are also established (Philips 2003, Parmar, 2010).

\section{Revisiting the scope of the model}

There are few aspects need to be considered and clarified when assessing the stakeholder theory in terms of its practicality and outcomes. The theory is evolving yet, it stimulates many controversy and complementary discussions. The scope of the theory is going parallel to the scope of management and ethic, yet changing global dynamics and power accumulation urge to look over it at both macro and micro economic level as the model tries to function in the mainstream economy which follows the neo classical synthesis in term of procedural and distributional justice versus company efficiency.

With the change of the power distribution in the global arena the role and importance of the businesses has increased tremendously. A silo approach to the scope of the theory does not resolve the core problems that the theory intent to resolve on how the values are created and traded, how the capitalism and ethics are connected and support managers for the issues related to value creation and value distribution.

Although the stakeholder theory represents a normative approach in terms of the ideal situation where the all stakeholders claims their stakes from the businesses, the model represents some boundaries which create a gap which are filled by the instrumental factors.

The ideal situation in the global economy would be equal distribution of the wealth throughout the stakeholders where all production and consumption efficiencies are in place, within equilibrium between the nations, societies, and the ecosystems where all species exists in harmony in a sustainable manner. This is entirely a holistic approach where normative measures are considered.

On the other hand, in reality, descriptive function of the economy is quite different. In the mainstream economy, rationality refers to rational management in either a business or a household, any goals are aimed at and achieved in line with the principle of the largest affect and rational behavior refers to inherently consistent way of behaving which enables consumer to achieve the maximum satisfaction (Zalega, 2012). The model considers profit maximization of the companies as an extension of the stockholder's rationalist intension. As per the model following the similar rationality measures, stakeholders also try to maximize the stakes from the business stakeholder relationship.

Companies are considered as the living entities survive in the economic ecosystem where social Darwinism takes place, which suggest the survival of the fittest (Steiner and Steiner, 2012). As companies have not completed their evolution yet, the survival mode is mostly defensive and destructive rather than constructive in many cases. As the companies do not have central nervous systems as the human beings have, the learning and reacting mechanism is not as fast and in most of the cases the functions are disconnected. The judgement of the 
behavior and consequence management is not done by the corporation system, rather it is done by the management team, if it applicable. This creates ambiguities regarding the justice in stakeholder theory.

\section{Justice versus efficiency}

As one of the critical tensions is related to the commitment of stakeholders from procedural and distributional justice compared to efficiency measures that is related to the instrumentality of the theory. If the rule of law is established clearly in the global market where most of the large companies and corporates take place, the procedural justice takes form of excellent procedural justice, which leads and supports the distributional justice that all the value created through the operations of the companies distributed fairly.

Managers work with the targets and analytics that require sustainable growth in the market. Most of the decisions are profit maximization driven, stockholder oriented, and target driven. In most cases the survival of the company and decision making is depend of the self-interest of the managers. The rationales of the decisions are based on the target achievement and competiveness of the company. In stakeholder theory one of the criteria is its relation to the financial output orientation which is supported with information (Freeman 2003).

In most cases, offshoring practices of the company by default, is in line with the cost efficiency purpose, carrying over the operations to other countries in order to get a competitive advantage using cost efficient labor, technology, resources and underservice market conditions. The cost of using disadvantaged nations' resources are low as in many countries as the laws are not established, some governments do not protect their domestic markets and the trade is deregulated. Therefore it is cost effective for companies extend their operations through supply chains by bypassing the rule of laws in international markets.

Although the laws are regulated at developed countries where most of the large companies operate, when the companies go global and carry their operations and markets to the other countries, the domestic rules do not always apply. As the rule of law has not been implemented globally, in most cases, driven with the self-interest, mostly in line with the profit maximization and cost minimization purpose, managers use procedural justice which ever fits their purpose most. The procedural justice remains pure procedural and distributional justice is omitted. In many cases managers in the companies make decisions for the sake of efficiency which in return minimize the production cost and maximize the opportunity while the decision may not be the most ethical.

\section{Normative basis of the model}

Stakeholder model has been evolved since it has been introduced (Freeman, 1984, Steiner and Steiner, 2012). The stakeholder theory follow the ground rules of Doctrin of Fair contract (Freeman 1994) with additional principles of Stakeholder enabling, director responsibility and stakeholder recourse which offers a normative basis for the theory. When we consider applicability of these principles, the instrumentalism of these elements toward the reality seems fair unless the corporates and the stakeholders integrate fully in a very agile and a lean environment.

Stakeholder theory aims to help managers to be aware of the value creation in an ethical way. In terms of consumer perspective, a need based approach has to be followed. Each individual is a consumer and mostly works for one of the businesses in various capacities, either as an employee, as a manager or as a stockholder. The roles are many times overlapped and crossed. The simple fact that, "we are each other's customers". Regardless of our business partnership in economy, we are seller of one or few products, but we are buyers of many. Value co-creation is mostly based on this principle. As stakeholder the interaction between the stakeholders are multilevel and multi facet which is related to a very simple basic phenomenon that has been overlooked. Therefore the rational attitude is to consider the economy from a holistic perspective. If the stakeholder theory can hold on to that point and the awareness of the parties are provided, instrumentalism of the theory would be enhanced.

\section{Construct of the suggested model}

Stakeholder model has been changed since it has been introduced by Freeman (1984). The government is introduced as another stakeholder and primary and secondary stakeholders were identified. Managers and employees and stockholders are the main decision makers and service providers in the company which co-creates the value together with the suppliers and customers. The main context here is acceptance of these stakeholders are "human beings", persons, in other words. Stakeholders are humans representing the institutions, holding positions, providing and using products and services. Each stakeholder takes decisions at various levels. from tactical to strategical. The stakeholder model works as a framework to strengthen the relationship between these stakeholders. As long as the companies are considered as tools or machines or systems created by human beings to create the value to serve the stakeholders, the stakeholder system would work.

On the other hand, each machine, system businesses work with the rules. Considering the globalization, if the rules of doing a business and creating the value is established properly with the basics principles of no harm, ethical production and lean innovation, which is extended to the entire supply chain, the sustainable ecosystem 
would be provided and the normative theory may be get closer to the descriptive theory. A Societal value cocreation established within the framework of corporate operation and governance. A legal surrounding would shape the limitation of the corporate actions and serves to the model as the border line. Government as a regulatory agency, with an effective functioning, can describe the legal framework that establishes a control mechanism for the market, the societal value co-creation aspect finds its place in the core of the model. A holistic model is depicted in Figure 2.

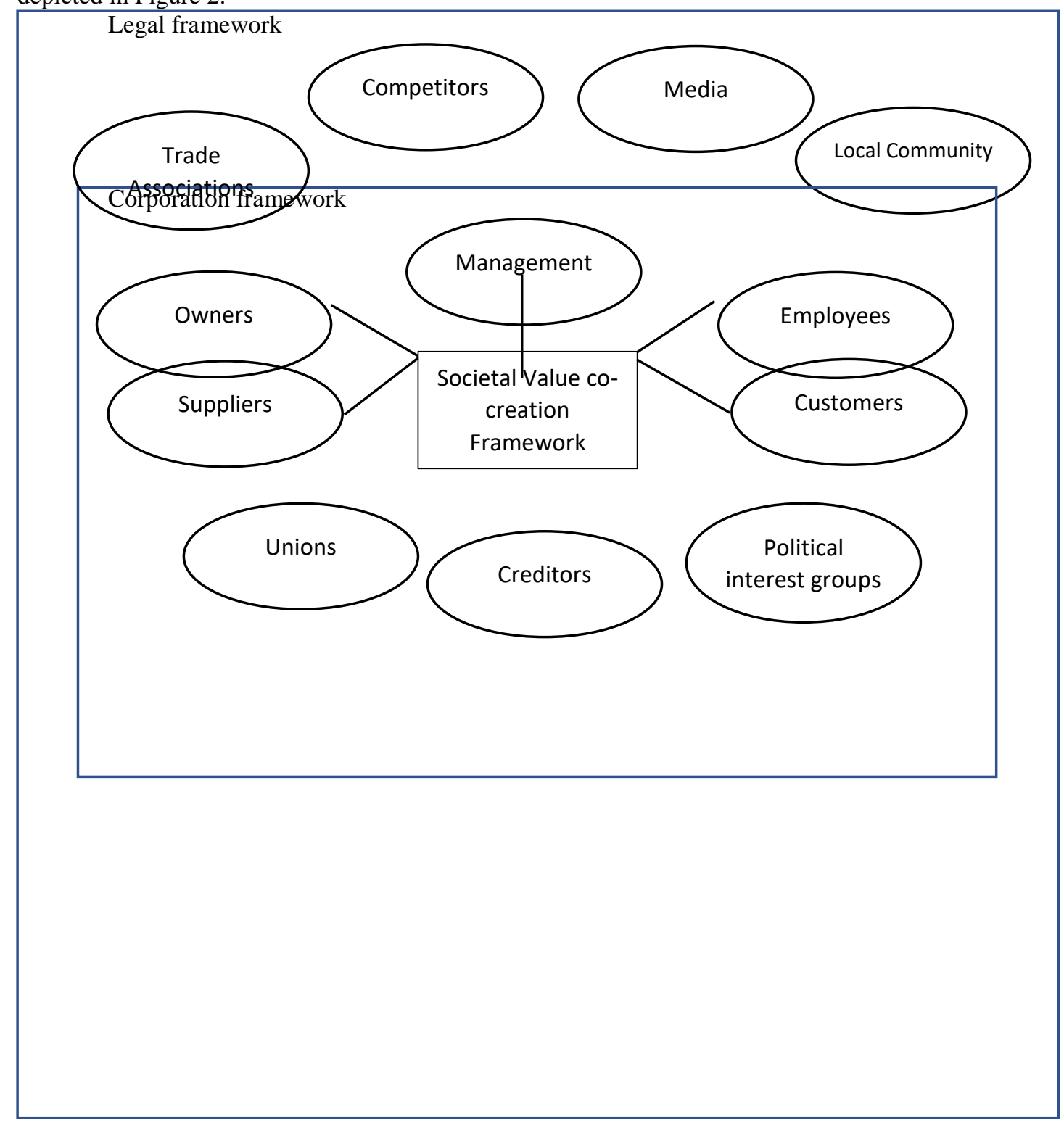

Figure 2. Restructured Holistic Model by the Author.

Basically the key element here is the connection with the economic theory although it is beyond the scope of the stakeholder theory as change has two directions; top to bottom, as government and law makers has a great responsibility on this and also bottom up, as the grass root level, that the primary stakeholders has to be aware of the morality of doing and consuming business. Companies should not be overrated rather the common well-being of the people has to be centralized. The suggestion would be the restructuring the model and change of the location of the company while keeping the stakeholder in tack, and put the corporation as a facilitator rather than the focal point of the model.

\section{Conclusion}

As companies are globalized, the technology is improved and communication is enhanced the societies started to interact closely Stakeholder theory is a powerful framework as an alternative to the business ethic. Although the 
company is considered as an entity, it is just a tool which has been built to serve the owners which interacts with the other tools in the market place. It is not surprising that the profit maximization is considered as priori and has not been challenged adequately as it works until it works. Challenging the basic rules of economy is not easy without suggesting a strong and applicable alternative, although the alternative is "profit optimization" rather than profit maximization. The human element in stakeholder theory can be emphasized when we consider the value creation and value distribution. It is also important to remember the overlapping responsibilities of the stakeholder as we are each other's customer. We depend on each other and we depend on the environment. We have to take care of both. Our normality has been shifted towards to being competitive as the current market conditions are unnecessarily harsh, driven by competition and profit maximization which drives many stakeholders to take unethical decisions at many levels. Eventually short term wins create long term loss.

Considering the given conditions, stakeholder theory is one of the strongest frameworks in order to make a difference in organizational management and business ethics. If the normative frameworks can be enhance towards the suggestion above and instrumental value is enhanced by the global business and low making level, our reality may shift towards a sustainable future. 


\section{References}

- $\quad$ Agle B.R \& Donaldson, T., Freeman, R. E., Jensen, M. C., Mitchell, R. K., Wood, D. J. (2008). Dialogue Toward Superior Stakeholder Theory . Business Ethics Quarterly. 18 (2), 153-190.

- Dubin, R. (1978) Theory development. New York: Free Press.

- Freeman R.E. (1994) The Politics of Stakeholder Theory: Some Future Directions Business Ethics Quarterly. 4 (4) 409-421.

- Freeman R.E. (1999) Divergent Stakeholder Theory, ACAD MANAGE REV April 1, 1999 24:2 233236;

- $\quad$ Freeman RE, Phillips RA. (202). Stakeholder Theory: A Libertarian Defense Business Ethics Quarterly 12(3) 331-349

- Freeman RE, Harrison JS, Wicks AC, Parmar BL, De Colle S.(2010). Stakeholder Theory: The State of the Art. Cambridge University Press: New York.

- Jones T.M. \& Wicks A. C. (1999). Convergent Stakeholder Theory ACAD MANAGE REV . 24 (2) 206221.

- Jensen M.C. (1989). The evidence speaks loud and clear. Harvard Business Review, 67(6): 186-188.

- Parmar, Bidhan L., Freeman, R. Edward, Harrison, Jeffrey S., Wicks, Andrew C., Purnell, Lauren, de Colle, Simone (2010), Stakeholder Theory: The State of the Art, Academy of Management Annals Vol. 4 (1) 403-445

- Phillips,R, Freeman RE \& Wicks (2003). What Stakeholder Theory Is Not. Business Ethics Quarterly 13, (4). 479-502

- Saunders H.D. (2014) Toward a neoclassical theory of sustainable consumption: Eight golden age propositions. Ecological Economics 105 (2014) 220-232.

- Steiner G. \& Steiner J. (2011) Business, Government and Society, (13th Edition). McGrawHill

- Viianova, L. 2007. Neither shareholder nor stakeholder management: What happens when firms are run for their short-term relevant stakeholder? European Management Journal, 25 (2): 146-62.

- Whetten D.A. (1989) What constitutes of a theoretical contribution. The Academy of Management review, 14 (4) 490-495

- Zalega, T. (2012). Rationality and methods of research into consumer market behavior. Equilibrium7(4) 77-99. 